\title{
The Role of Services Provided to the Industrial Complex in the Territorial Development of the Economy
}

\author{
Nail Shamilevich Satdinov \\ Department of Commerce, Service and Tourism \\ Samara State Economic University \\ Samara, 443090, Russia \\ sveta516@yandex.ru
}

\begin{abstract}
The transformation of the national economic structure, the deployment of the fourth industrial revolution, the initialization of network formations, the technological modernization of the industrial complex require new approaches to managing the sustainable development of economic systems. One of the tools for solving such important socio-economic problems is the formation and development of cooperation ties between the industrial complex and the service sector at the regional level. The phenomenon of efficiently functioning, sustainable in development due to internal sources and the potential of integration ties between the industrial complex and the service sector in Russian conditions at the regional level of management is rarely observed, which gives reason to believe that there are defects in existing management models and dictates the need to eliminate them. Using the Tatneft holding as an example, a methodology for assessing the effectiveness of the provision of services for petrochemical enterprises at the regional level is shown. We believe that this study can become a starting point for analyzing and assessing the effectiveness of the provision of services for industrial enterprises at the regional level, which can be included in the methodological recommendations for conducting production and economic activities of industrial companies.
\end{abstract}

Keywords-services, industrial complex, petrochemical industry, region, economic development of the region, holding, outsourcing.

\section{INTRODUCTION}

The relevance of the research topic is determined by the fact that with the transition of the Russian economy to a model of sustainable innovative development, new requirements are formed for the level of organization of managerial and production processes in an industrial complex, which can become a locomotive for activating production and economic activity. In addition, qualitatively new requirements are imposed on the content of strategies and the work of development institutions designed to ensure an increase in the scale of GDP and an increase in socioeconomic stability. The solution of these tasks will be facilitated by the expansion of the range of services provided in the industrial sphere, the strengthening of integration processes between economic entities of the real sector of the economy and the service sector, contributing to the pooling of resources, the distribution of risks of production and economic activities and an increase in the efficiency of industrial production. In this regard, it is necessary to revise and improve approaches to managing the sustainable development of the Russian economy based on the principles of service in industry.

Consequently, the transformation of the national economic structure, the deployment of the fourth industrial revolution, the initialization of network formations, the technological modernization of the industrial complex require new approaches to managing the sustainable development of economic systems. One of the tools for solving such important socio-economic problems is the formation and development of cooperation ties between the industrial complex and the service sector at the regional level. These initiatives are assigned an important role in those implemented at the state level as a whole, in individual regions, sectoral development programs and other program documents of a strategic nature. At the same time, the implementation of this policy finds practical application not only at the macro, but also at the meso-level, which predetermines the significance and relevance of these interactions for national and regional development. At present, it is no longer possible to ignore the fact of the complex nature of this issue, which affects the management of competitiveness, the development of innovative industrial clusters, network models, and ensuring sustainable economic growth in the region. It is not possible to achieve solutions to the problems of innovative, economic and social development of the country without the development of manufacturing industries, increasing the productivity of their functioning, which puts the development of links between industry and the service sector for industrial enterprises at the fore.

The issues of the relationship between the service sector and industry are increasingly being used at the meso-level, in particular, in the Strategy for the Socio-Economic Development of the Republic of Tatarstan until 2030, the region is one of the leaders in the implementation of the 
innovative development model, in which the policy of implementing a range of services for industrial enterprises is considered along with innovative and investment policies.

The phenomenon of efficiently functioning, sustainable in development due to internal sources and the potential of integration ties between the industrial complex and the service sector in Russian conditions at the regional level of management is rarely observed, which gives reason to believe that there are defects in existing management models and dictates the need to eliminate them. The solution of these and many other problems is achieved by using new approaches to the formation of the concept of management of sustainable development of industrial complexes, increasing their flexibility, adaptability and efficiency.

We believe that the interconnection of the research topic with such program documents of development at the federal and regional levels as the National Technological Initiative, the Decree of the President of the Russian Federation "On national goals and strategic objectives of the development of the Russian Federation for the period up to 2024", the state program of the Russian Federation "Economic development and an innovative economy ", Strategies for the spatial development of the Russian Federation for the period up to 2025, the Strategy for the socio-economic development of the Republic of Tatarstan until 2030, the draft Strategy for the spatial development of the Russian Federation for the period until 2025. Thus, the topic of this study is relevant and is closely related to the plans and priorities of the economic development of Russia and its regions.

The scientific literature should pay attention to the services provided for industrial enterprises, in particular: loyalty assessment models in industrial services [1], service quality assessment [2], organizational innovation [3], industrial growth through service innovation [4], make/buy decision [5], evaluating the effectiveness of services for industry [6], outsourcing [7,8], insourcing [9], supply chain strategies [10], innovation economy and service [11-14] et al. However, not enough attention is paid to the specifics of the provision of services for the regional industrial complex, which predetermined the choice of the topic of this study.

In this study, we will focus on studying the specifics, types and forms of services for the development of the petrochemical industry at the regional level of economic system management. The Republic of Tatarstan, which is one of the leaders in the development of the petrochemical industry in the Russian Federation, has a significant scientific, innovative and production potential for the formation and improvement of cooperation ties between the service sector and the industrial complex, was chosen as the object of research.

The subject of research in the article was the organizational and economic relations formed in the provision of services for petrochemical enterprises (for example, warehousing services). Calculated and analyzed in dynamics such indicators as the values of the gross margin and margin of the warehouse operator in the procurement activities, share of costs associated with storage and maintenance of the warehouse operator's warehouse in the procurement activities on the example of a regional holding structure PJSC TATNEFT.

Using the Tatneft holding as an example, a methodology for assessing the effectiveness of the provision of services for petrochemical enterprises at the regional level is shown, the main directions of cost accounting for the provision of services for enterprises in this sector of the economy are outlined, the advantages of outsourcing as a form of service provision for modern industrial companies are revealed. We believe that this study can become a starting point for analyzing and assessing the effectiveness of the provision of services for industrial enterprises at the regional level, which can be included in the methodological recommendations for conducting production and economic activities of industrial companies.

\section{METHODS}

General scientific methods of analysis and synthesis, as well as specific research methods, such as: monographic method, abstract-logical, computational-graphical, economicstatistical, comparative analysis, etc., were used as research tools.

\section{MAIN PART}

Most of the enterprises of the petrochemical complex are structurally holding-type entities. Such vertically integrated structures were formed during the planned economy and were recognized as ineffective in market conditions, since such a structure significantly complicates the development of competition. This aspect determines the specificity of sourcing services in the activities of enterprises in this area.

In order to study the forms of implementation of the service sector in the procurement activities of petrochemical enterprises, one of the largest manufacturers of this industry, which are holding structures, were analyzed using the example of the Republic of Tatarstan, as the main representative of the petrochemical regional industrial complex.

The characteristics of holding structures of the regional petrochemical complex are represented by the following enterprises and domestic products sold within the framework of sourcing:

Tire complex of PJSC TATNEFT: OOO UK TatneftNeftekhim; PJSC "Nizhnekamskshina"; OOO Nizhnekamsk Truck Tire Plant; LLC "Nizhnekamsk Tire Plant SSC"; JSC "Nizhnekamsktekhuglerod"; LLC "Trading house" Kama "; LLC Scientific and Technical Center Kama; JSC "Nizhnekamsk Mechanical Plant"; LLC Energoshinservice; JSC Yarpolimermash-Tatneft - car tires for various purposes; JSC "Group of Companies" Titan ": PJSC "Omskiy kauchuk", Omsk; LLC Novocherkask Lubricants Plant, Novocherkask; LLC "Poliom", Omsk; LLC Pskov Plant Titan-Polymer, Pskov; LLC "Titan-Agro", Omsk; LLC "Investkhimprom" Omsk; LLC "Titan-Inter-Trade" Omsk Rubbers; Synthetic latexes; products of organic synthesis; non-standard chemical equipment; gasoline for industrial purposes; lubricants; polypropylene; Production of chemical fibers and threads of the Belarusian State Concern for Oil and Chemistry: Branch "Plant Khimvolokno" OJSC "Grodno Azot", Grodno, Republic of Belarus - polyamide technical thread and cord fabric; cord and nylon thread; plastics; common consumption goods and other holding structures.

Next, we will analyze the specifics of the services provided to petrochemical companies of the regional economy, using the example of warehousing services, as one of the main types of services in industry. 
The costs of a warehouse operator in the petrochemical complex are primarily related to the form of organizing the provision of warehouse services and the degree of integration of the operator with the serviced enterprises. The set of costs arising in the course of the warehouse operator's activities includes:

1. Cost of procurement;

2. Storage costs;

3. Costs associated with lack of resources;

4. Costs associated with in-plant transportation of goods and materials and finished products;

5. The costs associated in a broad sense with the preparation and release from the warehouse, including production.

It should be noted that all the listed costs form the cost of warehouse operations and business processes, which is also influenced by macro and micro factors.

Macro-factors associated with the costly part of a warehouse operator's activities in the petrochemical complex differ from the set of factors that affect the income part of its activities.

So, among the macro-factors associated with warehouse costs, one can single out:

1. Prices for the purchase and / or construction of your own warehouse;

2. Tariffs for utilities (in the case of maintaining your own warehouse);

3. Rental rates for $1 \mathrm{~m} 2$ of warehouse space (in case of renting premises);

4. Tax rates (legislation);

5. The level of interest rates on loans and the cost of insurance services;

6. Prices in the procurement market for material resources;

7. Tariffs for storage and handling (in case of using the services of a public warehouse).

These macro-factors are closely intertwined with microfactors, which, in turn, have an equally significant impact on the warehouse operator's costs.

Among the micro-factors, the primary influence on the process of forming costs and their value is exerted by the ownership of the warehouse. This is one of the main decisions taken regarding the storage system. The warehouse, as you know, can be private, public and rented.

In any of the above options, such an aspect as warehouse capacity is important - the area of the warehouse and the parameters of warehouse equipment. The ability to store a certain amount and type of resources, the need for personnel depends on this. In addition, the volume of orders arriving at the warehouse and the intensity of their receipt have a strong influence on the rhythm of warehouse processes. They, in turn, depend on the volume of demand for a particular resource and the time of its submission to production, as well as the terms of its storage.

In addition to the above, the presence of a security system in the warehouse, as well as the presence of a personnel motivation system, has a significant impact on costs. They reduce the impact of risks associated with theft, damage and other loss of resources in the warehouse. For warehouses of petrochemical enterprises, security issues are especially acute, since the stocks stored in such warehouses are mostly hazardous and / or flammable substances, which requires enhanced fire safety measures.

Summarizing the above, it can be noted that all factors of the efficiency of warehouse services can have a positive and negative impact, depending on their vector orientation. The positive impact of the factor, other things being equal, leads to an increase in profits and a decrease in costs, that is, to an overall increase in efficiency.

All represented enterprises of enterprises of the regional petrochemical complex of the Republic of Tatarstan are holdings in their structure (or participants in holdings), while they have close ties with each other, since they are participants in the supply chains of the petrochemical complex.

More than half of the considered enterprises have a centralized form of organization of the supply of raw materials and materials, two enterprises are decentralized and one is mixed. At the same time, the form of organizing the provision of warehouse services correlates with the form of organizing supply. At the same time, all considered enterprises either have their own storage facilities, or have contractual relations for the lease of facilities from the enterprises of the holding, of which they are a part.

It should also be noted that only one of the considered enterprises - Kordiant OJSC - uses the services of third-party warehouse operators, while other enterprises have either their own subdivisions or a separate specialized enterprise within the holding (intracorporate outsourcer). At the same time, the warehouses provide a standard, in general, list of services: loading and unloading operations, preparation of shipment according to the formed requirements (quantity, timing, etc.), acceptance and safekeeping, etc. Two companies provide services to other legal entities: in OJSC "Kordiant" - on a contractual basis, services are rendered for warehouse processing and storage of goods to a certain list of partners of the company, which are directly related to the main activity (Offtake, temporary safekeeping of sold finished products); PJSC TATNEFT's internal outsourcer of the tire complex provides warehouse services to all enterprises of this subholding, as well as to a small extent to external organizations in terms of temporary storage warehouse services.

According to the information obtained as a result of the study of the enterprises in question, there are no supply disruptions, or they are insignificant and are covered by the available safety stock. This allows us to conclude about an efficiently organized supply system and the form of sourcing of warehouse services for each of the enterprises under consideration, however, it is not possible to assess the economic efficiency of the provision of warehouse services due to the lack of the necessary accounting system.

Half of the enterprises under consideration do not have a system of performance indicators, which can negatively affect not only the provision of warehouse services, but also the activities of the entire company, since the functions of analysis and control are key in the management of enterprises.

At the same time, all enterprises have an information system, including those of their own design, and also have certification in accordance with quality management standards required for suppliers of the automotive industry, 
JSC "Kordiant" also has certification in the Environmental Management System.

It can be concluded that, according to the presented data, the most flexible system of sourcing of warehouse services is possessed by JSC "Kordiant". However, the largest Russian tire manufacturer is the PJSC TATNEFT complex, the structure of which in terms of sourcing (in the form of intracorporate outsourcing) of warehouse services is of particular interest for research.

Such large companies as PJSC TATNEFT have significant production capacities, production volumes and need a stable and appropriate level of quality to provide production with various resources, materials, and, consequently, warehouse services provided efficiently.

To assess the efficiency of a warehouse operator, it is necessary to consider not only absolute, but also relative indicators. So, the gross margin of the company (the ratio of gross profit to sales) is the amount that the company sets to cover selling, management and other costs. The dynamics of the gross margin value is shown in Figure 1. It should be noted that this value is quite low, i.e. the warehouse operator receives about $3 \%$ of the profit from each ruble of revenue.

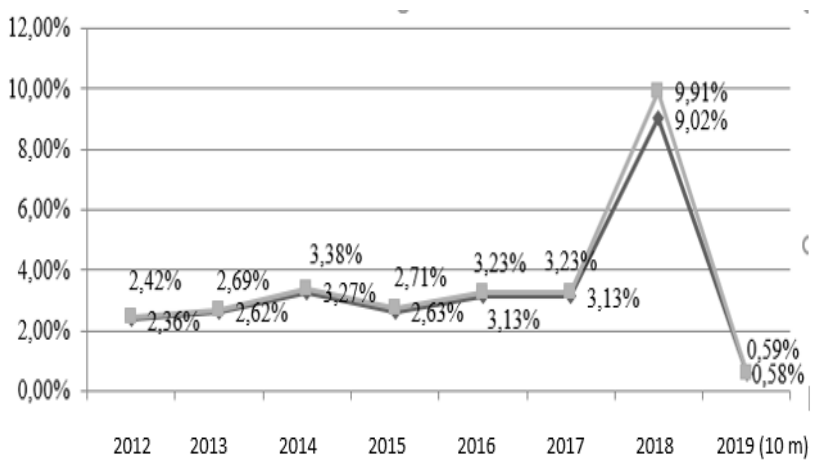

Fig1 The values of the gross margin and margin of the warehouse operator in the procurement activities of the tire complex of PJSC TATNEFT, 2012 - 10 months 2019,\%

However, another aspect of the activity of an intracorporate outsourcer of warehouse services is dependence on the parent company. Thus, the activities of the warehouse operator are subordinated to OOO MC TatneftNeftekhim, which, inter alia, within the framework of its controlling influence on the entire system of the tire complex, determines the amount of the margin at which the resources are sold to the production enterprises of the complex, setting it for a certain period time. The markup, in turn, is the ratio of gross profit to cost. Considering the fact that the cost of sales of the warehouse operator is practically equal to the revenue, the margin values are comparable to the value of the gross margin.

In general, over the period under review, the return on sales was low (less than 1\%). At the same time, the profitability of sales in terms of net profit took negative values in more than half of the periods, which actually reflects the unprofitability of the warehouse operator.

It should be noted that an intracorporate outsourcer is comparable to a 3PL operator in terms of the degree of integration and the list of services provided, while, according to the available data on the activities of market operators of warehouse services, the profitability of their activities is about $15-18 \%$. That is, according to this indicator, the internal corporate outsourcer of the tire complex of PJSC TATNEFT lags behind market operators. However, it is necessary to make a reservation that the majority of market operators provide services to commercial enterprises and have a different structure of warehouse operations, usually simpler.

Having considered the main performance indicators of the warehouse operator in the procurement activities of the tire complex of PJSC TATNEFT, it can be concluded that the efficiency of the activity decreases due to the increase in cost. At the same time, the prime cost is mostly the cost of purchasing material resources.

The economic mechanism for the formation of profit and profitability of the intra-corporate outsourcer of the tire complex of PJSC TATNEFT is directive in nature, which indicates the absence of a market approach to the formation of performance indicators of the research object. In other words, the question arises regarding the fairness of the establishment of this margin and its compliance with the real market situation. This fact underlines the negative aspect of the activity of vertically integrated structures and their influence on the distortion of the real market situation at the macro-level. Whereas with the development of market forms of sourcing, it is possible to form an "ecosystem" consisting of competing companies that become complimentors, creating usefulness to each other within the "ecosystem".

It should be noted that during the analyzed period, the share of costs for the maintenance of warehouses and storage was about $1.5 \%$ of the total costs of the warehouse operator (Figure 2). This value is insignificant relative to the total cost of the warehouse operator in the procurement of the tire complex of PJSC TATNEFT.

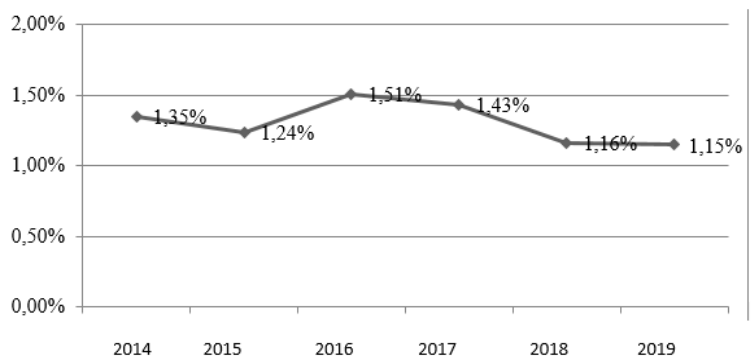

Fig2 Share of costs associated with storage and maintenance of the warehouse operator's warehouse in the procurement activities of the tire complex of PJSC TATNEFT in the total cost, 2014-2019,\%

It can be noted that the issue of effective inventory management can be considered as one of the most important aspects affecting the efficiency of a warehouse operator. It should be noted that for 2017-2019. The reserves of OOO TD Kama in terms of supplying production enterprises of the subholding show a constant significant growth, from 1.84 billion rubles to 4.1 billion rubles, or by $123 \%$, while the trade turnover grew by $17 \%$ (from 35 billion rubles in 2016 to 40.9 billion rubles in 2018). The excess of reserves over the standard was: $31.03 .19-65 \%, 30.06 .19-55 \%$. At the same time, there is a slowdown in inventory turnover, which is reflected in a decrease in the turnover ratio and an increase in the duration of one turnover for all divisions of the warehouse operator.

Thus, we can talk about a decrease in the efficiency of LLC TD" Kama on inventory management in the supply of 
enterprises of the tire business of PJSC TATNEFT. The reason for such a high rate of growth in the volume of reserves is the failure to fulfill the production plan by $65 \%$, as a result of which, due to the fulfillment of the concluded contracts for the supply of necessary resources, there was an accumulation of surplus reserves. It can be considered that in this case the activities of the intracorporate outsourcer were not ineffective, while there is a mismatch in the planning system in the holding.

The criterion for their effective implementation of supply activities is not exceeding the established amount of the limit, while the issues of optimality of procurement lots, as well as the general need for certain resources, which subsequently lead to the formation of excess stocks and illiquid assets, are not taken into account.

\section{CONCLUSION}

Having considered the possible forms of sourcing of warehouse services in the supply of petrochemical enterprises, a number of conclusions can be drawn:

1. The form of sourcing of warehouse services correlates with the form of organizing the supply of enterprises;

2. There is no clear decision-making mechanism regarding the choice of the form of sourcing;

3. There are no accounting systems to assess the effectiveness of warehouse services in the supply of petrochemical enterprises. Often, this task is not set in enterprises.

4. Most of the enterprises of the petrochemical complex do not use the services of third-party (market) warehouse operators, creating their own divisions that provide warehouse services, regulating the efficiency of their activities by administrative methods of influence.

Thus, at present there is no methodological basis for determining the optimal form of sourcing of warehouse services in the supply of petrochemical enterprises, and there is also no system for assessing the effectiveness of sourcing of warehouse services, and therefore, these issues require further study.

We believe that this study can become a starting point as a technique for analyzing and assessing the effectiveness of the provision of services for industrial enterprises at the regional level, which can be included in the methodological recommendations for conducting production and economic activities of industrial companies.

\section{REFERENCES}

[1] E. Giovanis, An. Tsoukatos, "Integrated model of the effects of service evaluation, corporate image, and switching barriers on customer loyalty“, Journal of Transnational Management, 2017, pp. 4 24.

[2] K. Kiran, S. Diljit, "Antecedents of customer loyalty: Does service quality suffice? "Malaysian Journal of Library \& Information Science., 2017 pp. $95-113$.

[3] M. Smith, "Factors influencing an organization's ability to manage innovation: A structured literature review and conceptual model“" International Journal of Innovation Management. 12(4), 2008, pp. 655676.

[4] R. Tucker, Driving Growth Through Innovation: How Leading Firms Are Transforming Their Futures (Business). San Francisco, CA: Berrett-Koehler Publishers, 2008.

[5] E.G.Jr. Anderson, G.G. Parker, The Effect of Learning on The Make/Buy Decision. Production \& Operations Management, John Wiley \& Sons, 11(3), 2002, 313 p.

[6] T. Tolstykh, D. Savon, A. Safronov, E. Shkarupeta, T. Ivanochkina, "Methods and Models for Analysis the Effectiveness of Industrial
Enterprises". Proceedings of the 32nd International Business Information Management Association Conference, IBIMA 2018 Vision 2020: Sustainable Economic Development and Application of Innovation Management from Regional expansion to Global Growth, 2018, pp. 7710-7722.

[7] N.E. Bitar, An Equilibrium Model of Integration Versus Outsourcing, Ph.D. Thesis. The University of Wisconsin. Milwaukee, USA, 2006 p.

[8] L. Cohen, A. Young, Multisourcing: moving beyond outsourcing to achieve growth and agility. Boston: Harvard Business School Publishing, $2005 \mathrm{p}$.

[9] O. Gassmann, B. Gaso, Insourcing Creativity with Listening Posts in Decentralized Firms. Creativity and Innovation Management. John Wiley \& Sons, 13(1),2004, pp. 3-14. DOI: 10.1111/j.14678691.2004.00289.x

[10] L. Li. Hau, Aligning Supply Chain Strategies with Product Uncertainties, California Management Review, Spring, 2012 p.

[11] T.I. Klimenko, A.I. Shinkevich, S.S. Kudryavtseva, M.V. Shinkevich, N.V. Barsegyan, A.A. Farrakhova, I.I. Ishmuradova, Modeling Factors of Environmental Tourism Development in Innovation Economy. Ekoloji, 27(106), 2018, pp. 263-269.

[12] A. I. Shinkevich, S. S. Kudryavtseva, G. G. Ivanov, O. N. Korotun, I. I. Ishmuradova, R. R. Gainullina, S. Sh. Ostanina, "Research and Technological Capacity of Russia as an Indicator of Knowledge Economy Growth“". International journal of advanced biotechnology and research, 8, 2017, pp. 156-163.

[13] A. I. Shinkevich, S. S. Kudryavtseva, A. N. Dyrdonova, D. K. Gallyamova, A. A. Farrakhova, E. I. Vodolazhskaya, "Assessment of the efficiency of energy-and resource-saving technologies in the model of open innovation“, E3S Web of Conferences 25 October 2019, DOI: https://doi.org/10.1051/e3sconf/201912404004

[14] A. I. Shinkevich, S. S. Kudryavtseva, I. G. Ershova, "Modelling of Energy Efficiency Factors of Petrochemical Industry". International Journal of Energy Economics and Policy, 10(3), 2020, pp. 465-470. DOI: https://doi.org/10.32479/ijeep.9396 